\title{
Papers
}

\section{Perinatal mortality in rural China: retrospective cohort study}

\author{
Zhuochun Wu, Kirsi Viisainen, Ying Wang, Elina Hemminki
}

\begin{abstract}
Objectives To explore the use of local civil registration data to assess the perinatal mortality in a typical rural county in a less developed province in China, 1999-2000.

Design Retrospective cohort study. Pregnancies in a cohort of women followed from registration of pregnancy to outcome of infant seven days after birth.

Setting Routine family planning records in 20 rural townships in eastern China.

Subjects 3697 pregnancies registered by the local family planning system during 1999.

Main outcome measures Abortions, stillbirths, early neonatal mortality, perinatal mortality.

Results Only three cases were lost to follow up. The average age of the women at pregnancy was 25.9 years. Three hundred and twelve pregnancies were aborted and 240 ended in miscarriage (total 552, 15\%). The perinatal mortality rate was 69 per 1000 births, the rate of stillbirth was 24 per 1000 births, and the early neonatal mortality was 46 per 1000 live births. The early neonatal mortality was 29 in boys and 69 in girls per 1000 live births. The perinatal mortality rate increased notably with parity and was higher in townships having lower income per capita.

Conclusions The family planning system at the most local level is a useful data source for studying perinatal mortality in rural China. The perinatal mortality rate in the study county was higher than previously reported for both rural and urban areas in China. The results by parity and sex of the infant raise concern over the impact of the one child policy.
\end{abstract}

\section{Introduction}

In China the reported estimates of the perinatal mortality rate in the 1980s-1990s have shown quite a large variation: from 10 to 19 per 1000 in well developed urban areas ${ }^{12}$ and from 20 to 30 per 1000 in moderately developed urban areas. ${ }^{34}$ Reliable data from rural areas have not been available in the international literature, while in Chinese studies the rates have varied from 18 to 49 per $1000 .^{5-7}$ These studies, however, were based on cross sectional household interviews. Since the mid-1990s there have been no reported studies of the perinatal mortality rate in rural China.

We used routine data locally collected by the family planning system to describe the perinatal mortality in a typical rural area in a less developed province in China.

\section{Methods}

Reproductive health care in China has been strongly influenced by its one child population policy. Contraception services are controlled by family planning authorities who officially authorise all pregnancies, while care for pregnancies and births is provided mainly within the public healthcare system. The details of the population policy and its implementation have varied over time and between provinces. Financial and other incentives have been used to encourage people to follow the policy regulations, and discouragement of larger families has included financial levies on each additional child and other sanctions. ${ }^{8}$ Since the mid-1980s, many provinces have implemented a more flexible policy: rural families with one daughter and no sons were allowed to have a second child.

We studied a county in a rural area in eastern China, in which most of the population of nearly 900000 is engaged in farming. The county covers almost 3000 square kilometres, mostly of flatland. In terms of national gross domestic product rankings it is typical of less developed rural areas in China.

The healthcare system consisted of county hospitals and decentralised healthcare services at the township and village level. Specialised obstetric services were available only at county level; in township hospitals midwives cared for normal births, but there were usually no systematic prenatal care services. Private clinics in villages were officially not involved in pregnancy or birth care. All three levels of health care functioned on a fee for service basis, and most farmers paid for all health services themselves.

The local family planning system was also organised at three levels. The county level authorities supervised the national policy, but its implementation took place mainly at township and village level. In townships, medically trained staff provided services at family planning stations, including organising and performing systematic pregnancy testing, abortions, and insertions of intrauterine devices. In each village there was one female family planning worker who provided contraceptives, assisted in pregnancy testing, and reported population events (including miscarriages, abortions, stillbirths, live births, and neonatal deaths) to township authorities.

In the family planning system, married women aged 20 to 49 years were required to undergo a pregnancy test every two or three months. In the case of a pregnancy unauthorised by family planning regulations or marriage law, the woman would be persuaded to have an abortion. Otherwise she and her partner would be fined about $£ 300-700$ (\$500-1200, €430-1000). In addition to the fine, state employees could lose their jobs or be demoted.

\section{Data collection}

We carried out a retrospective cohort study of pregnancies that occurred between 1 January and 31 December $1999(n=3697)$ in 20 selected townships. The data used were collected as pre-intervention baseline data for a controlled trial on the introduction of systematic prenatal care in rural China. Data were col- 


\section{Definitions used in study}

Maternal age: age when pregnancy was registered

Parity: number of live children at time of pregnancy

Gestational age: calculated from registered date of last menstrual period (weeks)

Stillbirth: fetal death between 28 weeks' gestation and delivery,

calculated per 1000 births

Early neonatal mortality: death in first seven days after birth,

calculated per 1000 live births

Perinatal mortality rate: stillbirths and deaths in first seven days, per 1000 births

lected from 20 of 55 eligible towns. Two sets of data were used: pregnancy outcome data and township socioeconomic data.

A trained local field research assistant abstracted the data on pregnancies and their outcomes from the original handwritten work records of the village family planning workers. The records included data on all women who had a positive pregnancy test result and on the outcome of pregnancy so that each outcome could easily be linked to the respective woman. The data collection occurred at township level where the records of each village were brought each month for the compilation of statistics. The subsequent outcomes of the pregnancies in the 1999 cohort were followed up in family planning records in 1999 or 2000. The variables related to the women's backgrounds were each woman's birth date, township of residence, and number of living children. Variables related to pregnancy were the date of the last menstrual period and miscarriage or abortion. The infant variables were sex, singleton or multiple birth, birth order, live birth, stillbirth, and early neonatal death.

The socioeconomic data were collected from the county statistical bureau. The bureau estimates the average annual net income of farmers by interviewing a random sample of 30 households from each township. The farmers' net income is the average annual income minus tax and the cost invested in production; this figure was used as the socioeconomic variable for each township. The selected townships were representative of the study county in terms of socioeconomic background: the farmers' net annual income per capita in the 20 study townships was $\$ 270$ and in the whole county it was about $\$ 260$.

The box shows the definitions we used in the study. We calculated relative risks and their confidence intervals for comparison between parity, infant sex, and township groups.

\section{Results}

There were 3697 pregnancies in the cohort, resulting in 3092 live births in a total population of 299463 . The average age at pregnancy was 25.9 years (data on age were missing for $4 \%$ ), and $3142(85 \%)$ women were younger than 30 years. There were no registered pregnancies among women under the age of 20 years,

Table 1 Pregnancy outcomes in rural China by parity (\%)*

\begin{tabular}{|c|c|c|c|c|c|}
\hline & $\begin{array}{c}\text { Para } 1 \\
(n=2255)\end{array}$ & $\begin{array}{c}\text { Para 2 } \\
(n=1409)\end{array}$ & $\begin{array}{c}\text { Para } \geq 3 \\
(n=11)\end{array}$ & $\begin{array}{c}\text { Total } \\
(n=3697 \dagger)\end{array}$ & $\begin{array}{c}\text { Relative riskł } \\
\quad(95 \% \mathrm{Cl})\end{array}$ \\
\hline Miscarriage & 3.9 & 10.4 & 0.0 & 6.5 & 2.67 (2.20 to 3.67 ) \\
\hline Induced abortion & 1.0 & 20.5 & 0.0 & 8.4 & 20.40 (13.18 to 30.47$)$ \\
\hline Stillbirth & 1.2 & 3.3 & 0.0 & 2.1 & 2.75 (1.60 to 4.46$)$ \\
\hline Live birth & 94.6 & 66.2 & 100.0 & 83.6 & 0.70 (0.67 to 0.73$)$ \\
\hline
\end{tabular}

*Pregnancy outcomes total over $100 \%$ because there were 24 pairs of twins and one set of triplets.

†Includes 22 women of unknown parity.

†Calculated for para 2 with para 1 as reference group.

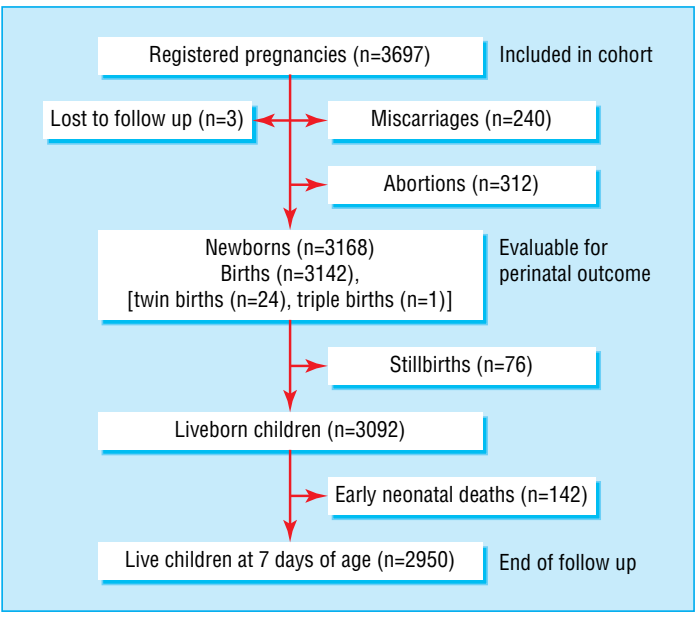

Flow chart of follow up and outcomes of study cohort

and only 15 women were older than 35 years. Of the women, 2255 (61\%) were childless, 1409 (38\%) had one child, and 11 had two children before this pregnancy (parity data were missing for 22).

The cohort was easily traced in the records, and only $0.1 \%$ of pregnancy outcomes were missing from registration. There were 240 miscarriages and 312 abortions (552, 15\% of total). Seventy six pregnancies (2\%) ended in stillbirth and $3092(85 \%)$ in a live birth (figure). The proportions of both stillbirths and miscarriages among second births were almost three times higher than the proportions for first births, and the proportion of abortions increased 20-fold from first to second pregnancies. Only $66 \%$ of second pregnancies ended in a live birth (table 1).

The perinatal mortality rate was 69 per 1000 births (table 2). If we counted the 30 abortions in which the gestational age was more than 28 weeks as perinatal deaths, the perinatal mortality rate would be as high as 78 per 1000 . About two thirds of the perinatal deaths occurred in the early neonatal period. Both the stillbirth rate and early neonatal mortality increased with parity. The risk of a stillbirth in a second pregnancy was almost four times that for a first pregnancy, while the risk of an early neonatal death doubled.

The birth rate in the study townships was 10.3 per 1000 total population per year, 6.2 for male infants and 4.1 for females, giving a sex ratio of 152 males for 100 females. Early neonatal mortality was twice as high for female as for male infants. The sex difference in early neonatal mortality was mainly attributable to mortality in second births. Early neonatal mortality in male infants was not affected by parity, while in female infants it increased dramatically with parity, being nearly six times higher

Table 2 Perinatal outcomes in rural China for all births* by parity

\begin{tabular}{|c|c|c|c|c|}
\hline & $\begin{array}{c}\text { Para 1 } \\
(n=2161)\end{array}$ & $\begin{array}{l}\text { Para 2 } \\
(\mathrm{n}=980)\end{array}$ & $\begin{array}{c}\text { Total } \\
(\mathrm{n}=3168 \dagger)\end{array}$ & $\begin{array}{c}\text { Relative riskł } \\
(95 \% \text { CI) }\end{array}$ \\
\hline Stillbirth rate§ & 12.5 & 48.0 & 24.0 & 3.84 (2.41 to 6.12$)$ \\
\hline Stillbirth rate§ీ & 14.3 & 72.6 & 33.1 & 5.08 (3.36 to 7.68$)$ \\
\hline \multicolumn{5}{|c|}{ Early neonatal mortality**: } \\
\hline All & 31.4 & 77.2 & 45.9 & 2.46 (1.78 to 3.40$)$ \\
\hline Male & 28.6 & 29.2 & 29.2 & 1.02 (0.58 to 1.75$)$ \\
\hline Female & 34.9 & 205.8 & 69.0 & 5.90 (3.91 to 8.93$)$ \\
\hline Perinatal mortality§ & 43.5 & 121.4 & 68.8 & 2.79 (2.15 to 3.62$)$ \\
\hline
\end{tabular}

*Live births: para $1=2134$, para $2=933$, total $=3092$.

$\dagger$ Including 11 births to women of para $3+$ and 16 to women of unknown parity. $\ddagger$ Calculated for para 2 with para 1 as reference group. $\S$ Per 1000 total births (stillbirths and live births).

ๆlncluding 30 induced abortions after 28 gestational weeks. **Per 1000 live births. 
Table 3 Perinatal outcomes in rural China in all births* by wealth of township

\begin{tabular}{|c|c|c|c|c|}
\hline Perinatal outcomes & $\begin{array}{c}\text { Highest } \\
\text { quarter FNI } \\
(\mathrm{n}=887)\end{array}$ & $\begin{array}{c}\text { Middle FNI } \\
(\mathrm{n}=1656)\end{array}$ & $\begin{array}{l}\text { Lowest } \\
\text { quarter FNI } \\
(\mathrm{n}=625)\end{array}$ & $\begin{array}{l}\text { Relative risk† } \\
(95 \% \mathrm{Cl})\end{array}$ \\
\hline Stillbirth rateł & 19.2 & 27.8 & 20.8 & $1.08(0.53$ to 2.21$)$ \\
\hline 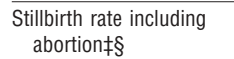 & 26.8 & 39.4 & 25.5 & 0.95 (0.51 to 1.77$)$ \\
\hline Early neonatal mortality? & 33.3 & 44.1 & 68.6 & 2.06 (1.30 to 3.27$)$ \\
\hline Perinatal mortality $\neq$ & 51.9 & 70.7 & 88.0 & $1.70(1.16$ to 2.48$)$ \\
\hline
\end{tabular}

$\mathrm{FNI}=$ farmers' net annual income per capita.

*Live births: highest quarter $=870$, middle quarters $=1610$, lowest quarter $=612$.

†For lowest quarter with highest quarter as reference.

$\ddagger$ Per 1000 total births (stillbirths and live births).

§Includes abortions at $>28$ weeks' gestation.

१Per 1000 live births.

for second births than for first births (table 2). The relative risk of early neonatal mortality for girls compared with boys in the second birth was 7.15 (95\% confidence interval 4.35 to 11.76 ), while there was no significant difference between the sexes among the first born infants (1.22, 0.76 to 1.95$)$.

Parity did not differ by the socioeconomic status of the township (data not shown in tables). Perinatal mortality was negatively associated with the wealth of the township (table 3). The differences between townships were caused by early neonatal mortality, which was higher in townships of lower socioeconomic status, while the stillbirth rate, whether calculated with or without the late abortions, was not affected by the wealth of the township.

\section{Discussion}

\section{Data quality}

We have shown that routine data collected locally can yield useful information on perinatal mortality. In most developed countries, the data source for perinatal mortality is the routine vital statistics registration system. In China this is available only in urban areas, where most perinatal statistics are hospital based. The reliability of such statistics has been questioned because of under-reporting of deaths at home. ${ }^{9}$

This was the first community based cohort study in China that used data collected routinely by the family planning system at village level. The chosen data source proved effective in following up pregnancies to their outcomes, as in only three out of 3697 cases were the outcome data missing. In China, where family planning policy and its implementation are given top priority at all levels, collection of pregnancy data is also prioritised. Families have a specific incentive to report miscarriages, stillbirths, and infant deaths to the family planning system as this leads to authorisation for a new pregnancy.

The age and parity distribution of the study cohort reflected the restrictions on childbearing from marriage law and family planning policy. Most second pregnancies occurred within the regulated circumstances, and registered third pregnancies were rare.

\section{Potential bias}

Our data source, however, had possible biases. Although the whole cohort with a registered pregnancy was followed up, some unregistered pregnancies might have occurred, particularly if the parents managed to hide the pregnancy from the village family planning worker. Pregnancies in unmarried women were culturally unacceptable and therefore likely to be hidden and to end in abortion in the private sector.

There might also have been misclassification of cases in the registers. Though determination of fetal sex is illegal, it may occur in urban and rural areas. ${ }^{10}$ If the woman then has an abortion such pregnancies, if registered, might appear as miscarriages or stillbirths in the registers, which would perhaps partially explain the increase in the rate of miscarriages and stillbirths by parity. Pregnant women were also inclined to report a later than actual date for their last menstrual period to gain time in which to determine the sex of the fetus. Therefore, the detected stillbirth rates are probably underestimated.

However, as the village family planning worker was responsible for an average population of 1000 in a relatively small area, she would generally be aware of pregnancies among her clients. Married women staying away from their home villages for long periods of time were required to regularly mail back family planning certificates for pregnancy testing. The control system was therefore comprehensive.

\section{Perinatal mortality}

Perinatal mortality in this cohort was much higher than that for urban areas in the $1980 \mathrm{~s}-1990 \mathrm{~s}$ in China. ${ }^{2-4}$ The rate in the study cohort was also higher than any reported rate from specific studies in rural areas. ${ }^{5-7}$ Studies in which calculations of infant mortality were not based on epidemiological surveys, however, have been shown to underestimate rates by more than $50 \% .{ }^{11} \mathrm{In}$ the previous interview studies on perinatal mortality, interviewees may have been reluctant to tell the investigators about late abortions, stillbirths, and deaths of infants.

According to the World Health Organization, in the late 1990 s the average perinatal mortality rate in low income countries was 57 per 1000 (range $40-70$ per 1000). The perinatal mortality rate in our study was higher than that reported in a case-control study in India (53 per 1000$)^{12}$ and in a prospective cohort study in rural Malawi (65 per 1000, including all fetal deaths after 22 weeks' gestation). ${ }^{13}$

In several developing countries the perinatal mortality rate is higher in populations with lower socioeconomic status. ${ }^{12}{ }^{14}$ We also found an inverse association between perinatal mortality and economic status of the township. Although the average income in the study townships was representative of the whole county, due to eligibility criteria for the trial the study townships might have been slightly better off in terms of access to health

\section{What is already known on this topic}

Data on perinatal mortality in China rely on surveys and hospital based statistics

The perinatal mortality rate in urban China has been reported to be lower than in other developing countries and is inversely associated with socioeconomic status

There have been few reports on perinatal mortality for rural China

\section{What this study adds}

Routine statistics collected by the Chinese family planning system were a reliable data source for the study of perinatal mortality

The perinatal mortality rate in rural China was much higher than previously reported rates from urban areas and was associated with parity in a different way than in other countries 
services. Therefore it is likely that the perinatal mortality rate would have been even higher if all townships had been included.

The Chinese have a history of preferring sons, especially in rural areas. ${ }^{10}{ }^{15}$ Most Chinese farmers still depend on their sons for security in old age in the absence of a pension or medical insurance. The study province implemented a modified family planning policy, allowing second pregnancies when the first born is a girl. The search to secure a son in the second pregnancy may have contributed to the high rates of abortion in second pregnancies as well as to higher neonatal mortality among girls.

In this cohort, in which most women were under 35 years of age and lived in a cultural context where smoking among women is rare, the rate of stillbirth increased strongly from first to second pregnancies, contrary to the situation in developed countries. ${ }^{16}$ This might be due to the misclassification of some abortions as stillbirths.

The higher early neonatal mortality in second born compared with first born children, particularly in girls, was probably also a result of both the family planning policy and the preference for sons. This is reflected in the high male to female sex ratio among the liveborn children in the cohort. We are currently investigating mortality by infant sex and the issue of sex ratio at birth.

We thank Duolao Wang for his helpful comments.

Contributors: ZW, KV, and EH conceived and implemented the study, conducted the analysis, and wrote the manuscript. YW assisted in data analysis and writing. ZW is guarantor of the paper.

Funding: Academy of Finland.

Competing interests: None declared.

Ethical approval: The study was approved by the STAKES ethics committee, 11 January 1999.

1 Zhang J, Cai WW, Chen H. Perinatal mortality in Shanghai 1986-1987. Int J Epidemiol 1991;20:958-62.
2 Xu BZ. Perinatal mortality in China and Finland with specific reference to sex differentials. Oulu: Acta Universitatis Ouluensis Medica, 1995.

3 Li XT, Yu YP, Shen YT. The perinatal mortality from 1983 to 1993 in Wuhu city. (In Chinese.) Zhomg Guo Fu You Bao Jian 1995;10:246-8.

4 Liu XH, Yi RT, Yao JR, Lei W. Perinatal mortality in the past 10 years in Chengdu, Sichuan province. (In Chinese.) Zhong Guo Shi Yong Fu Chan Ke Za Zhi 2001;17:111-2.

5 Wei YZ, Cui HZ Perinatal mortality in Guizhou province 1987. (In Chinese.) Gui Yang Yi Xue Yuan Xue Bao 1992;17:42-5.

6 Yao JS, Chen YZ, Xi BL, Jiang YZ, Li WS, Wang H. Systematic prenatal care management in rural areas. (In Chinese.) Zhonghua Fu Chan Ke Za Zhi 1991;26:224-7.

7 Zhu XL, Er XD. Maternal and child health status in Shanshan County. (In Chinese.) Xin Jiang Yi Xue Yuan Xue Bao 1996;19:83-5.

8 Kane P, Choi CY. China's one child family policy. BMJ 1999;319:992-4.

9 Zhong Guo Ren Kou Nian Jian. (In Chinese.) Beijing: Institute of Population Studies, 2000 .

$10 \mathrm{Chu}$ JH. Prenatal sex determination and sex-selective abortion in rural central China. Pop Dev Rev 2001:27:259-81.

$11 \mathrm{Mu}$ L. Appraisal of an infant mortality indicator used in evaluating primary health care services. (In Chinese.) Zhong Guo Chu Ji Wei Sheng Bao Jian 1995;9:34-5.

12 Shah D, Shroff S, Ganla K. Factors affecting perinatal mortality in India. Int J Gynaecol Obst 2000;71:209-10.

13 Kulmala T, Vaahtera M, Ndekha M, Koivisto A-M, Cullinan T, Salin M, et al. The importance of preterm births for peri- and neonatal mortality in rural Malawi. Paediatr Perinat Epidemiol 2000;14:219-26.

14 Shah NM, Shah MA, Khalaf AA, Mustafa MM, Al-Sayed A. Searching for socio-economic risk factors in perinatal mortality in Kuwait: a case control study. Soc Sci Med 2000;51:539-50

15 Banister J. China's changing population. Stanford: Stanford University Press, 1987.

16 Raymond EG, Cnattingius S, Kiely JL. Effects of maternal age, parity, and smoking on the risk of stillbirth. Br J Obstet Gynaec 1994;101:301-6.

(Accepted 30 September 2003)

bmj.com 2003;327:1319

School of Public Health, Fudan University, 138 Yi Xue Yuan Road, Shanghai 200032, China

Zhuochun Wu associate professor

Ying Wang research assistant

National Research and Development Centre for Welfare and Health, PO Box 220, 00531 Helsinki, Finland

Kirsi Viisainen senior researcher

Elina Hemminki research professor

Correspondence to: $\mathrm{Z}$ Wu

zcwu@shmu.edu.cn 